\title{
Design of district emergency operations centres, and the case study of Indian Oil Corporation Jaipur depot explosion
}

\author{
Kailash Gupta \\ University of North Texas, \\ Denton, TX 76201, USA \\ Email: kailashgupta@my.unt.edu
}

\begin{abstract}
The author of this paper was appointed by the Government of Rajasthan state in India to design Emergency Operations Centers (EOC) at district level. The assignment was to submit an implementable practical report of district level EOCs design for equipment, personnel and training. This paper describes the process used for this design. A list of priority equipment, staffing pattern and specific training programmes were suggested. On the basis of the recommendations, EOCs have been set up in all the 33 districts of Rajasthan. The case study of the explosion at the Indian Oil Corporation's Jaipur depot illustrates the use of alternative field EOC in responding to the explosion and the relevance of the EOC consultant's recommendations in responding to the disasters. The objectives of this paper are to share the experiences of designing EOCs in a developing country, and the methods of optimisation for meeting objectives under resource constraints.
\end{abstract}

Keywords: EOC; emergency operations centres; EOC design; Rajasthan; alternate EOC; district; District Collector; Indian Oil Corporation Ltd.; Jaipur; oil explosion.

Reference to this paper should be made as follows: Gupta, K. (2010) 'Design of district emergency operations centres, and the case study of Indian Oil Corporation Jaipur depot explosion', Int. J. Emergency Management, Vol. 7, Nos. 3/4, pp.221-232.

Biographical notes: Kailash Gupta is pursuing $\mathrm{PhD}$ in Interdisciplinary Information Science with specialisation in Emergency Management at the University of North Texas, Denton, USA. His paper 'A new philosophy in EOC design: the case of Rajasthan State in India' was awarded the best practice paper at The International Emergency Management Society (TIEMS) Annual Conference, Beijing, 2010. He has done US National Science Foundation funded research after the tsunami in Sri Lanka and India, after cyclone Aila in Bangladesh and India, and after the earthquake in Haiti.

\section{Introduction}

The Indian Famine Commission of 1878 probably gave the first famine relief management system in the world. Over the years, India has documented and developed a well-established relief system after famine and drought. The system was further developed for providing relief after sudden onset disasters, and not only creeping 
disasters. However, there is a paradigm shift from post-disaster relief to pre-disaster prevention, preparedness and mitigation in recent times internationally, and particularly in India. Therefore, the State Government of Rajasthan, in India, appointed the author of this paper as a consultant to design an Emergency Operations Centre (EOC) at the district level in February 2007. The consultant submitted his report in May 2007. The recommendations in the consultant's report were accepted and district level EOCs are established in all the 33 districts of Rajasthan.

This paper is intended to share the experiences and 'best practices' of the resulting effort in design and implementation of EOCs under resource constrains. It is hoped that the paper will benefit other countries and individual states or provinces within them that are planning to establish EOCs.

The paper starts with the genesis of the idea of having district EOCs, and then proceeds with situation analysis, sources of information, thesis, methods/process, recommendations for setting up district EOCs and implementation. The IOC case study is covered in the sections of IOC and its Jaipur depot, fire explosion and its causes, damage due to fire explosion, response to the explosion and the role of the alternative field EOC. The paper ends with discussion, limitations and conclusion.

\section{Design of district EOCs}

\subsection{Genesis}

The National Disaster Management Authority (NDMA) of India was set up under the Disaster Management Act of 2005. NDMA is the apex body for disaster management headed by the Prime Minister and has the responsibility for laying down policies, plans and guidelines for disaster management. To facilitate capacity building, training community stakeholders, conducting research, documentation and a national repository of information, the National Institute of Disaster Management (NIDM) was created. The NIDM, in partnership with other research institutions, works within the framework of broad policies and guidelines laid down by the NDMA (Ministry of Home Affairs, n.d.).

There is a Calamity Relief Fund (CRF) in India for meeting the expenditure for providing immediate relief to the victims of disasters. The Government of India contributes $75 \%$ of the yearly allocation to CRF and the balance is met by the respective state governments. A total of Rs. 110 billion (nearly US\$ 2.2 billion) was provided for the CRF for the five financial years from 2000-2001 to 2004-2005 (National Disaster Management Division, 2003, p.72). It is not known how much was provided during the same period for pre-disaster prevention, preparedness and mitigation, but it would almost certainly have been miniscule, compared to post-disaster relief.

The Government of India was persuading the state governments to set up the EOCs expeditiously as mandated in the Disaster Management Act of 2005 at various levels. The Government of India eased the norms, allowing for procurement of essential search, rescue and evacuation equipments including communication equipments subject to a ceiling of $10 \%$ from the CRF allocation of the year (National Disaster Management Division, 2003). The Government of Rajasthan seized this opportunity to establish the district level EOCs and appointed the author as a consultant. The brief given to this author was to prepare an actionable/implementable report on EOC design. 


\subsection{Situation analysis}

Rajasthan is the largest state in India in terms of geographical area (342,239 sq km). $77 \%$ of the population ( 57 million in 2001) of the state live in rural areas. The population density is 165 persons per sq $\mathrm{km}$, compared to 324 per sq $\mathrm{km}$ for India. Rajasthan has been vulnerable to floods, recurrent drought and earthquakes. During the last 60 years, there have been only six years when some or the other part of the state did not suffer from a drought.

Rajasthan is divided into seven divisions and 33 administrative districts. The Divisional Commissioner basically does planning, coordination and monitoring works with the District Collectors within his division. The Collector and District Magistrate (popularly called Collector) is the administrative head of a district. The District Collector is responsible for disaster management within the district, apart from other administrative functions. However, below him there was no government official who was employed full-time for disaster management and there were no functioning permanent EOCs in the districts of Rajasthan, except in the Jaipur and Hanumangarh districts. Temporary district EOCs were set up during monsoon season for flood control by transferring people from Public Works, Irrigation and other departments of the government.

\subsection{Sources of information}

Kendra and Wachtendorf (2003, p.52) studied the reconstruction of New York City's EOC after 9/11, and came to the conclusion that training and preparation are fundamental for a resilient organisation. However, 'creative thinking, flexibility and ability to improvise in newly emergent situations are vital'. The pre-existing relationships helped in meeting the communication challenges.

EOCs have been in existence in the USA since the1970s as focal points for disaster response. According to Quarantelli (1979), the six functions that an EOC performs are coordination, policymaking, operations management, information gathering, public information and hosting visitors. Neal (2003, p.35) reviewed literature on EOCs and concluded that "little systematic or empirical information is available to guide their effective design ... a systematic analysis is needed to determine how to design and configure effective EOCs". He continued by saying that we need objective data to improve EOC design and effectiveness. "At this time we do not know what does work and does not" (p.38). Comparing the American and Canadian experience about the role of EOCs in emergency management, Scanlon (1994) confirmed that the Canadian experience coincided with the American regarding the problems faced by the EOCs. These problems included forced relocation of EOCs in the disaster impact area and lack of clarity in many instances as to who was managing the EOC (Quarantelli, 1978). Scanlon examined 19 incidents in Canada and concluded that the need for an EOC was being increasingly accepted in Canada.

Review of disaster literature led to an understanding that an EOC is a pre-designated facility established in a community for centralised direction and coordination of the overall response and to support the administration during an emergency. Responding organisations converge at the EOC during an emergency to coordinate response, recovery, information gathering and resources. EOC is "a function, a place, and a structure" (Perry 1991, p.204). The EOC optimises communications and coordinates efficient resource allocation and information presentation. The facility also helps in 
executive decision making for disaster management in all the four phases of response, recovery, preparedness and mitigation. Therefore, the EOC needs to have an inbuilt capacity of scaling up according to the requirements in case of activation.

\subsection{Thesis}

The use of EOCs in smaller jurisdictions remains sporadic, sometimes improvisational and poorly understood (Wenger et al., 1989). Perry (2003, p.151) noted that "EOC standards and use are challenges in the United Kingdom (Alexander, 2003), Europe (Triligia, 1996), and Australia (Emergency Management Australia, 1996)". According to Perry, emergency managers do not understand the functions and structure of an EOC.

There is hardly any literature systematically describing the creation and design of EOCs in either developed or developing countries. This paper aims to fill this gap in literature by describing the process by which district level EOCs were designed and created in Rajasthan. A case study of the use of EOC in the Indian Oil Corporation Jaipur Depot explosion is presented as an illustration.

\subsection{Methods/process}

The Principal Secretary, Disaster Management and Relief Department, Government of Rajasthan, sent a concept note on EOC prepared by the author of this paper to all the District Collectors in Rajasthan. The objective was to educate Collectors about the EOC and get their involvement in the design of EOC itself. A questionnaire was attached to the concept note, asking for the existing facilities and practices, and their suggestions in terms of equipment, staffing and training needs. 12 of the 33 districts returned usable responses.

To understand the situation on the ground, the EOC designer conducted field visits to 11 districts. During the field visits, group interviews were held with Collectors and disaster management related staff. Focus groups were held in five districts with the help of the Collectors. The focus group participants were Collectors, Assistant District Magistrates, district officials, representatives of non-profit organisations, Red Cross, Scouts, National Cadet Corps, Civil Defence and others involved in disaster management in the districts. The consultant also met Divisional Commissioner of Bikaner.

There is a community-based trained volunteers organisation established under the Civil Defence Act, 1968. In 2003 they were allowed to be used for disaster management. This author interacted with the Civil Defence Volunteers who were undergoing the initial training. Discussions were also held with the Dy. Controller, Civil Defence, Jaipur; Civil Defence and Home Guard Instructors, and in charge of Civil Defence and/or Home Guard in the districts visited. The Consultant attended disaster management related video conference of states with the NDMA, state video conference with the District Collectors, and had discussions with the officials of the National Informatics Center (NIC) ${ }^{1}$ in Rajasthan. Meetings were also held with the Director and officials of the IT \& Communication Department of Govt. of Rajasthan.

The research methodology relied on primary data such as survey questionnaires, face-to-face interviews, focus groups, field observations, field research and case studies as well as secondary data such as document analysis of the relevant official files and internet research. 


\subsection{Recommendations for setting up district EOCs}

Based on results from the research, a consultancy report was presented to the Government of Rajasthan. The main recommendations are given below.

\subsubsection{The role of the district EOC}

1 The district EOC will play a key role in district disaster planning, response and recovery.

2 The district EOC shall pull together people and resources to handle emergencies that are outside the ability of single department to handle.

3 The district EOC is the key to managing the district's disaster efforts through the centralised, coordinated efforts of government officials, response agencies and community volunteers by establishing priorities.

4 The district EOC will provide a means of centralising and managing communications and information within the EOC, between the EOC and the Incident Commander in the field, and between the EOC and the public. The EOC provides ready access to all available information and simplifies information verification, evaluation and display.

5 The EOC will have the resources and trained personnel to handle not only sudden catastrophe but also creeping disasters, like drought. It will help in resource acquisition, re-allocation and management. The EOC also provides staff continuity and facilitates staff changes.

6 Regular training and exercises will be conducted by the district EOC.

7 Documentation management will safeguard documents generated or received by the EOC for use after an emergency.

8 The alternate EOC, backup power and communications equipment will ensure continued operations in even the worst conditions (if the main district EOC becomes dysfunctional or inaccessible, it would be possible to perform the emergency operations from the alternative EOC).

\subsubsection{Equipments recommended for EOC}

In case of activation of the EOC, the Incident Commander needs to come to the EOC. The Emergency Support Function coordinators also need to come to the EOC for proper response. Special emphasis needs to be given to communication and database equipments. The EOC should have a radio system, a media interface emergency broadcast system, a mobile communication van and mobile command centre to which essential function can be transferred immediately in an emergency, if necessary. In case of a catastrophic incident, a helicopter surveillance facility should be available. There has to be a seamless, robustness and inbuilt redundancy in the equipments so that in case of failure replacement is possible thereby increasing the reliability. A public-emergency call system was recommended. The EOC should have facilities to telecast/broadcast warnings 
to the public without the intervention of the public or private controlled TV channels or radio stations. All district EOCs should be equipped to trigger public warning sirens. Runners, traditional drum beaters (Suno, suno, suno...), ${ }^{2}$ vehicle mounted public address system and public address systems used for namaz by mosques may also be used for warning.

The use of GIS and GPS with seven vehicle tracking units is recommended for the state. The EOCs may be equipped to make reverse emergency calls and send SMS messages on the cellphones in the target areas of the district. It was recommended that the district alternative EOC should have at least basic minimum functionality for responding to disasters. The district alternate EOC for the Jaipur district and the state as a whole was suggested for setting up at the Center for Disaster Management, HCM Rajasthan Institute of Public Administration, and this could be used for training as well. A list of equipment with priorities was suggested for procurement in the first phase.

\subsubsection{Staffing pattern for EOC}

There was a need for standard staffing patterns in all the 33 districts of Rajasthan. The staffing pattern could consist of District Disaster Management Coordinator, IT \& Communication Officer and four Dispatchers for $24 \times 7$ emergency call centre. The EOC staff could be used for preparation and updating of district disaster management plans, creation of databases, preparation of a history of incidents, training and related activities. The EOC is to be continuously used to be effective during disasters.

\subsubsection{Training of EOC personnel}

The need for training cannot be overemphasised. During a disaster the Incident Commander has to take decisions while generally not knowing what the needs (demands) are; where the resources (supplies) are and when and how the goods and services will arrive (logistics). When every second counts and it is a matter of life and death, disaster management requires one of the highest levels of professional competence.

To start off, there is a need for training the District Collectors. The design of a training programme on emergency response, complete with duration and contents of each session for District Collectors and Additional District Magistrates, was given in the Consultant's report (Khanna and Gupta, 2004). A list of the 50 most recommended books for graduate students in emergency management and related fields by the disaster researchers and emergency management faculty in the USA was included in the consultant's report (Gupta, 2005). Disaster management is everybody's business and many a times it is the community action which works initially. Thus, a proposal for training ‘Community Disaster Response Teams' was given.

\subsection{Implementation/setting up of district EOCs}

The consultancy report on Design of EOCs at District Level by Kailash Gupta was accepted by the Government of Rajasthan. EOCs in all the 33 districts of Rajasthan have been set up. 


\subsubsection{Equipments}

Most of the equipment recommended for purchase in the first phase in the consultancy report were approved for purchase, and were procured. The existing state EOC was strengthened. Mobile command vehicles with GPS vehicle tracking unit and software were recommended for seven divisional headquarters. These were procured at an aggregate cost of Rs. 3,423,798 $(\$ 73,630)$ by the General Administration Department of the government and are being used.

Thirty-three sets of following equipments were purchased, one set for each district:

1 Desktop computers at Rs. 88,650 (\$2429)

2 Multifunction printers (print, scan, fax, copy) at Rs. 14,327 (\$308)

3 42” Plasma TVs with DTH at Rs. 45,625 (\$981)

4 VHF wireless sets, six numbers for each district at an aggregate cost for the 33 districts of Rs. 2.2 million $(\$ 47,000)$

5 Digital cameras at Rs. $8850(\$ 190)$

62 KVA online UPS at Rs. 49,548 (\$1066)

7 Emergency diesel generators at Rs. 129,671 (\$2789)

8 Telephone landline and cellphone

9 Broadband connectivity

103 ISDN line with feature phone cabling/networking

11 Dragon light and ropes

12 Display boards for emergency contact numbers

13 White boards.

RajCOMP, a State Agency, established under the Department of IT\&C, Government of Rajasthan, was assigned the task of purchase of equipment for the District EOCs. The equipment purchased by RajCOMP and the costs incurred are given above. The costs are given for indicative purposes only and vary depending on the specifications, tax structure and many other considerations. The purpose of giving the costs is to explain the EOCs could be set up even under resource constrains. The items listed above for which costs are not given were purchased by the District Collectors locally.

\subsubsection{Staffing pattern for EOC}

Due to the resource constrains with the government, no fresh recruitment or deployment of full-time dedicated staff for the EOCs was resorted to. An innovative solution was found to give additional duties to the District NIC Officer (please see Note 2) and make them responsible for the District EOC. Even the EOC equipment was placed in the district NIC centres. In some of the districts, one of the Additional District Magistrate was made in charge of the EOC. In the state capital Jaipur, the incumbent Deputy Controller, Civil Defence, was made District EOC Officer, in addition to his normal duties. 


\subsubsection{Training of EOC personnel}

Again due to the resource constraints no specialised training in disaster management or EOC operations was provided to the EOC staff. In absence of dedicated full-time EOC personnel, it becomes difficult to decide whom to train.

\section{Case study of the Indian Oil Corporation Jaipur depot explosion}

On 29 October 2009 at 7:30 pm first explosion fire started in the Indian Oil Corporation Ltd. (IOC) depot (or terminal) at Sitapura Industrial Area, Jaipur, that raged for 11 days, killing 11 people, evacuating half a million people and keeping the city in smoke for the duration. The explosion was equivalent to 20 tonnes of TNT, and created an earthquake of 2.3 on the Richter scale. Even the army was pressed into action for response (MSN News, 2010). An onsite temporary field EOC was set up in the office premises of Rajasthan State Industrial Development and Investment Corporation Ltd. (RIICO) at Sitapura. This alternative field EOC was used for 11 days, the period that the fire raged.

\subsection{IOC and its Jaipur depot}

The IOC is a Government of India owned company in the field of oil and gas, petrochemicals, refinery, pipeline transportation and marketing. IOC turnover in 20092010 was US\$ 57 billion and it employed 34,363 employees (IOC, 2010). Jaipur, the capital city of Rajasthan and a popular tourist city, has a population of over 2.5 million. IOC Sitapura terminal is situated $16 \mathrm{~km}$ south of the city centre. Jaipur city is $260 \mathrm{~km}$ southwest of New Delhi. In the vicinity of the depot when it was set up years ago, there was hardly any habitation nearby. But now there is Sitapura Industrial Area adjoining the IOC terminal having many industrial units, educational institutions and residential areas.

The IOC website immediately after the explosion or till now does not mention about the explosion, although it mentions ironically about many safety awards IOC won. The annual report for 2009-2010 on pages 46-47 states "An unfortunate incident of fire occurred in Indian Oil's Jaipur terminal on 29th October, 2009 resulting in the loss of lives as well as destruction of property and products", without giving any details.

This author was not allowed to enter the terminal for collection of data for this paper by IOC, although ten months had elapsed after the fire. The General Manager of the IOC Rajasthan Office refused to meet me or give any information, saying that the matter is subjudice. In July 2010, the IOC General Manager for Rajasthan and eight of his senior colleagues were arrested. They were charged under Section 304A of the Indian Penal Code (causing death due to negligence) along with certain sections of the Petroleum Act. The officials have been held responsible for gross violations of norms laid down by the Oil Industry Safety Directorate (OISD) (Business Standard, 2010).

\subsection{Fire explosion and its cause}

There was leakage in oil transportation which could not be contained. It was a leak that subsequently caused the fire and engulfed all the 11 storage tanks at the depot. First oil tanker explosion occurred at about 7:30 pm on Thursday, 29 October 2009. There were 11 interconnected tankers. Due to the heat, cap of other tankers blew up and oil got burnt. One after the other all the tankers caught fire, which could be seen from kilometres away. The fire could not be contained until all the oil burnt out. 
The Ministry of Petroleum and Natural Gas of the Government of India appointed a seven member committee headed by M.B. Lal, former Chairman-cum-Managing Director of the Hindustan Petroleum Corp. Ltd., to investigate the causes of the explosion. The committee report pointed out the 'gross negligence' during the transfer of petrol from the storage tank. "The basic or root cause is an absence of site specific written operating procedures, absence of leak stopping devices from a remote location and insufficient understanding of hazards, risks and consequences", Lal told reporters a day after submitting the inquiry report to Petroleum Minister Murli Deora (Rediff, 2010).

\subsection{Damage due to fire explosion}

The fire balls kept coming and smoke engulfed the city and the surrounding areas. Many buildings of the nearby industries were destroyed, and the glass of buildings even kilometres away was broken. The petrol vapours in the atmosphere made it difficult for people to breath. There was death of 11 people, six of them IOC employees, three employees of the adjoining Genus Company (manufacturing electronic house energy meters and invertors), one elderly woman from Sitapura village and another unknown person. There is common boundary wall between IOC depot emergency exit gate and Genus. One employee of Genus died because the administrative building fell on him, while two died near the boundary wall. People died due to burns and asphyxia. Over 300 people were injured.

One of the persons this author interviewed was living very near to the depot. Although most of the people and his family members evacuated on 29 October, he and another neighbour stayed put throughout the night outside their home. He said it was too hot and every three minutes he was feeling thirsty and was drinking water. Due to the intense odour, even breathing was difficult. There was carbon layer in the morning all around. Small iron pieces of tankers were found all around.

\subsection{Response to the explosion}

Administration, police, fire brigade, ambulance, army, civil defence volunteers and other services were immediately deployed for response. All the hospitals, government and private, were put on high alert, and injured were taken to the nearest hospitals. The $5 \mathrm{~km}$ radius area from the depot was cordoned off and declared 'danger zone'. All movements in the danger zone were restricted, including the nearby railway movement. Half a million people were evacuated. The electricity to the danger zone was intentionally disconnected immediately to avoid any untoward incidents.

The technical matter of containment of fire was discussed by the fire officials with the IOC officials. Technical experts of IOC also came from Mumbai. However, they did not have any solution to stop burning of oil tankers till all the oil got burnt out. An attempt was made to prevent the fire from spreading out. On the west side of the IOC depot, on the other side of the highway there is depot of Bharat Petroleum Corporation. Luckily the wind direction itself prevented the fire from going toward that side. Firefighting trucks were called from adjoining cities and were placed all around the cordoned off declared danger zone. In some places trenches five feet wide and deep were dug and filled with water to prevent fire from spreading. 


\subsection{Role of the alternative field EOC}

RIICO is a state government catalyst agency employing 1054 persons for industrial development (RIICO, 2010). Its office in Sitapura Industrial Area, near the IOC Depot, was visited by the administration officers in the night of 29 October itself. The office building has four big rooms in the second floor which were and still are empty. The ground level has offices with computer, telephone, fax, copiers and other facilities. The RIICO office was used as a field EOC for response to the fire explosion for the 11-day duration till the fire raged. The Jaipur district disaster officials, fire brigade, police, ambulance, civil defence and other responding organisation officials used the facility for coordination and meeting.

\section{Discussion}

Some of the equipment has been purchased and delivered to the respective districts for setting up EOCs. However, in some districts, the equipments have not been installed. VHF Wireless sets were not operative, pending allocation of frequency by the Wireless Planning and Communications wing of the Government of India.

The IOC explosion clearly brings forth the relevance of the consultant's recommendations about disaster response and role of the EOC. For example, there is no siren warning system in Jaipur. This is another matter that the loud explosion sound, explosion-triggered earthquake, fireballs visibility from kilometres, smoke and odour themselves served as warnings. The incident also explains the importance of mobile communication and command centre to function as field EOC. VHF Wireless system of the EOC would have been useful. The existing wireless system connects only the Collector with the senior police officers.

The explosion incident also supports the recommendation for the employment of the full-time dedicated district disaster management team. The training of the District Collectors and other officials in disaster management is also essential.

One of the District Collectors, who does not want to be identified, said "The EOC is ill equipped and is not functional. There are no resources. The EOC requires dedicated professional disaster manager. Disaster management is a specialized discipline, and generalists cannot do disaster management. The staff who are presently assigned to the EOC have no disaster management expertise".

Without proper staff and training, any amount of sophisticated equipment would be useless. Therefore, the Government of Rajasthan should seriously consider appointing permanent staff at the district EOCs and their training.

\section{Limitations}

I did not face any major challenges or limitations in conducting the EOC study. The officials at the State Government, District Collectors and others were very helpful. The only limitation and challenge appears to be lack of understanding and knowledge about the disaster management in general and the functioning of EOC in particular. My findings confirm Perry's (2003, p.151) findings that emergency managers do not understand the functions and structure of an EOC. 
As already stated, the IOC did not cooperate in giving any information for research of this paper. The Jaipur District Collector and the district disaster officer did provide the relevant information.

\section{Conclusions}

On the basis of my recommendations, EOCs in all the 33 districts of Rajasthan were set up by procuring equipment. A comparative study of setting up EOCs in other states of India and even in other developing countries would be of interest. A properly functioning EOC in disaster response is important to save lives, property and environment during and after a disaster. This paper is expected to help in better understanding of issues involved in design of EOCs under resource constrains for the benefit of administrators, emergency/disaster managers, researchers and students. The IOC explosion explains the importance of equipping district EOC, alternative EOC, full-time dedicated team of disaster management officials and proper disaster management training.

\section{References}

Alexander, D.A. (2003) 'Towards the development of standards in emergency management training and education', Disaster Prevention and Management, Vol. 12, No. 2, pp.113-123.

Business Standard (2010) IOC to seek bail for its nine Jaipur officials, 4 July 2010, New Delhi. Available online at: http://www.business-standard.com/india/news/ioc-to-seek-bail-for-itsnine-jaipur-officials/400287/ (accessed on 31 August 2010).

Emergency Management Australia (1996) Australian Emergency Manual, Emergency Management Australia, Canberra.

Gupta, K. (2005) Graduate Level: Body of Knowledge - 50 Most Recommended Books for Graduate Students in Emergency Management and Related Fields, Emergency Management Institute, Emmitsburg, USA. Available online at: http://www.training.fema.gov/EMIWeb/ edm/readinglist.asp (accessed on 30 May 2008).

Indian Oil Corporation Ltd. (IOC) (2010) Annual Report 2009-2010, Indian Oil Corporation Ltd., Mumbai.

Kendra, J.M. and Wachtendorf, T. (2003) 'Elements of resilience after the World Trade Center disaster: reconstituting New York City's emergency operations center', Disasters, Vol. 27, No. 1, pp.37-53.

Khanna, B.K. and Gupta, K. (2004) Training Program on Emergency Response submitted to National Institute of Disaster Management, Government of India, New Delhi, Unpublished.

Ministry of Home Affairs (n.d.) National Disaster Management Policy, Government of India. Available online at: http://www.ndmindia.nic.in/ (accessed on 12 February 2010).

MSN News (2010) Human error caused Jaipur IOC terminal fire, probe shows, 2 February 2010. Available online at: http://news.in.msn.com/business/article.aspx?cp-documentid=3598500 (accessed 14 February 2010).

National Disaster Management Division (2003) The List of Items and Norms of Expenditure to be Followed by the States for Incurring Expenditure from the Calamity Relief Fund (CRF) and the National Calamity Contingency Fund (NCCF) for the Period Between 2000-2005Revision Thereof, Ministry of Home Affairs, Government of India, DO Letter No. 32-3//2003NDM I dated 23 April 2003, NDM Division, New Delhi, India.

Neal, D.M. (2003) 'Design characteristics of emergency operating centers: what we know and don't know', Journal of Emergency Management, Vol. 1, No. 2, pp.35-38. 
Perry, R.W. (1991) 'Managing disaster response operations', in Drabak, T.E. and Hoetmer, G. (Eds): Emergency Management Principles and Practice for Local Government, International City Management Association, Washington, DC, USA.

Perry, R.W. (2003) 'Emergency operations centers in an era of terrorism: policy and management functions', Journal of Contingencies and Crisis Management, Vol. 11, No. 4, pp.151-159

Quarantelli, E.L. (1978) Uses and Problems of Local EOCs in Disasters, Disaster Research Center, Newark, DE, USA.

Quarantelli, E.L. (1979) Studies in Disaster Response and Planning, Final Project Report No. 24, Disaster Research Center, Newark, DE, USA.

Rediff (2010) Probe faults IOC management for Jaipur fire, 2 February 2010. Available online at: $\mathrm{http} / /$ business.rediff.com/report/2010/feb/02/probe-faults-ioc-management-for-jaipur-fire.htm (accessed on 31 August 2010).

RIICO (2010) RICCO at a Glance. Available online at: http://www.riico.com/glance.htm (accessed on 31 August 2010).

Scanlon, J. (1994) 'The role of EOCs in emergency management: a comparison of American and Canadian experience', International Journal of Mass Emergencies and Disasters, Vol. 12, No. 1, pp.51-75.

Triligia, A. (1996) 'Training policy and civil protection in Italy', Stop Disasters, Vol. 20, No. 29 , pp. $20-31$.

Wenger, D., Quarantelli, E.L. and Dynes, R. (1989) Disaster Analysis, Disaster Research Center, Newark, DE, USA.

\section{Notes}

1 National Informatics Centre (NIC) is the premiere Science and Technology institution of the Government of India, for providing e-Government/e-Governance solutions adopting best practices, integrated services and global solutions in government sector.

2 Traditional drum beaters attracting the attention of citizenry used to go around the town for making public announcements in India. They would shout suno, suno, suno in Hindi language, which means listen, listen, listen. Subsequently when people are gathered, they would make the public announcement. 